\title{
The Role of Translanguaging in Computational Literacies
}

\author{
Documenting Middle School Bilinguals' Practices in Computer Science Integrated Units
}

\author{
Sara Vogel \\ The Graduate Center, City University of New York \\ New York, NY \\ Laura Ascenzi-Moreno \\ Brooklyn College, City University of New York \\ Brooklyn, NY
}

\begin{abstract}
Bilingual education has described a process called translanguaging by which students use linguistic resources across and beyond multiple named languages to learn. Here, we examine how bilingual learners translanguage while learning computer science. These middle schoolers participated in a curricular intervention which infused computational thinking into their Spanish-English bilingual language arts class. Through a descriptive qualitative methodology, we document classroom moments supporting four claims: 1) students' translanguaging blurs linguistic, disciplinary, and modal boundaries, 2) computational literacies are intertwined with students' other literacies , 3) students' attitudes about language and the contexts around them play a role in their translanguaging, and 4) students translanguage to engage in specific $\mathrm{CT}$ practices.
\end{abstract}

\section{CCS CONCEPTS}

- Social and professional topics $\rightarrow$ Computational thinking; K-12 education; Cultural characteristics;

\section{KEYWORDS}

Computer Science for All, Middle School, Bilinguals, Translanguaging, Computational Literacies, English Language Learners

\section{ACM Reference Format:}

Sara Vogel, Christopher Hoadley, Laura Ascenzi-Moreno, and Kate Menken. 2019. The Role of Translanguaging in Computational Literacies : Documenting Middle School Bilinguals' Practices in Computer Science Integrated Units. In Proceedings of the 50th ACM Technical Symposium on Computer Science Education (SIGCSE '19), February 27-March 2, 2019, Minneapolis, MN, USA. ACM, New York, NY, USA, 7 pages. https://doi.org/10.1145/3287324. 3287368

\section{INTRODUCTION AND THEORETICAL FRAMEWORK}

Humans use language as a primary way to communicate and to learn. This is as true in computer science as it is in other school

Permission to make digital or hard copies of all or part of this work for personal or classroom use is granted without fee provided that copies are not made or distributed for profit or commercial advantage and that copies bear this notice and the full citation on the first page. Copyrights for components of this work owned by others than the author(s) must be honored. Abstracting with credit is permitted. To copy otherwise, or republish, to post on servers or to redistribute to lists, requires prior specific permission and/or a fee. Request permissions from permissions@acm.org.

SIGCSE '19, February 27-March 2, 2019, Minneapolis, MN, USA

() 2019 Copyright held by the owner/author(s). Publication rights licensed to ACM. ACM ISBN 978-1-4503-5890-3/19/02 .. \$15.00

https://doi.org/10.1145/3287324.3287368

\author{
Christopher Hoadley \\ New York University \\ Brooklyn, NY \\ Kate Menken \\ Queens College, City University of New York \\ Queens, NY
}

subjects. Translanguaging, a recent theory from the fields of applied linguistics and bilingual education, posits that people fluidly call into action their full meaning-making repertoires, including their linguistic resources (e.g. knowledge of Spanish and/or English vocabulary), semiotic resources (e.g. drawing, intonation) and social practices (e.g. conventions for greeting, joking, etc.) [13]. Translanguaging argues that the way people - especially bilingual and multilingual people - assemble language features often defies categorization into traditional named languages (like "Spanish" or "French") [29]: in a single interaction, people may use words from multiple languages, gestures, and even emoji and other resources from the environment and technology to make meaning.

Translanguaging is a relevant theory to apply in K-12 CS learning environments. In such classrooms, students are not just expected to write compilable code, they are expected to collaborate to produce meaningful projects for particular users, to deepen their understanding of concepts in a particular subject area, and to think critically about the impacts of technology [2]. In these activities, language takes on a central role. Students communicate to a range of audiences using dynamic configurations of spoken and written human and programming languages, through modalities such as comments in code, paper prototypes, UML diagrams, and a host of other resources: in other words, they translanguage. In introducing translanguaging to the CS education field, we do not equate programming languages with named languages like French or Chinese (as some states have controversially done by enabling students to fulfill foreign language graduation credits with CS courses [4]), but rather recognize the ways computer science is taught and learned with and through language.

As CS for All initiatives are implemented in more schools serving multilingual students, it's imperative to consider the role that students' language resources might play in learning. There is, however, an absence of research documenting translanguaging in CS education. How do students, especially emergent bilinguals (students with diverse linguistic backgrounds who may be learning English in school), draw upon their diverse language repertoires? How might teachers support students to translanguage in ways that promote engagement with CS concepts and practices? How can classroom communities work across language differences so all can learn? Past studies demonstrated how "talk, specifically, when used consciously and productively in an introductory CS curriculum for young learners can shape the process of development of CT [computational thinking]" [16]. We build on this by considering how students make meaning in CS ed using language beyond "talk," 
and how their language use is shaped by their diverse profiles and experiences. Translanguaging has been mentioned in CS education studies of Indian tertiary schooling contexts, mostly to describe how teachers used both English and Hindi [30] or Tamil [32] to teach programming to students who have been schooled through a vernacular language. Those studies, however, do not provide researchers and practitioners with an understanding of the characteristics of students'-especially young bilingual students'-language practices while they engage in CS, and the relationship of students translanguaging to computational thinking concepts or practices.

In this paper, we report preliminary findings from a study we conducted using a descriptive qualitative research methodology at a bilingual Spanish-English middle school program where teachers infused computational thinking into other subjects. Specifically, we document a series of classroom moments which help support four main claims: 1) students' translanguaging practices in CS learning contexts blur linguistic, disciplinary, and modal boundaries; 2) computational literacies are intertwined with the many other literacies students bring with them; 3) students' language attitudes and activity contexts around them play a role in their translanguaging; 4) students translanguage in order to engage in specific CT practices (like remixing and abstraction). Finally, we discuss how evidence of translanguaging among bilingual learners has implications not only for how bilingual students might learn computer science but for understanding monolingual learners' use of language during CS activities, and how teachers might support students to translanguage purposefully while they learn CS.

\section{RESEARCH CONTEXT}

\subsection{Bilingual Students and CS Education}

The context for this study is a research practice partnership (RPP) called Participating in Literacies and Computer Science (PiLaCS), which grapples with a core problem of practice facing schools and districts implementing CS for All policies: how to meaningfully include emergent bilingual students. The linguistic diversity of the country's school-aged student population is the highest it has ever been [19]. The close to 10 percent of the US public school students that are classified as "English Language Learners" [5] often face many challenges as they navigate the school system: nearly 60 percent of ELLs in every state live in families whose income falls below 185 percent of the federal poverty line [15], they often attend schools of variable quality [8] where administrators and teachers have limited knowledge about language learning and bilingualism [26], they are unfairly evaluated by assessment policies that measure them against monolingual English standards [24], and often experience subtractive models of education that do not build on their language or cultural backgrounds [25]. For these and other factors, emergent bilinguals graduated at below-average rates (66 percent to 84 percent nationally in the $2015-16$ school year) [3]. There is no data available on the rates of these students' participation in CS education.

\subsection{The New York City Context}

The home base of our RPP is New York City, where this problem of practice is a particularly important one. Here, the Department of Education has committed to teaching CS perspectives, practices, and concepts in at least one meaningful, 10-25 hour instructional unit per grade band (K-2, 3-5, 6-8, 9-12) to all 1.1 million students in NYC. While there are tools such as the NYC DOE Computer Science Education Blueprint [27] to guide this implementation, there are few resources for teachers of emergent bilinguals. In NYC, $41 \%$ percent of students speak languages other than English at home [28], and $12.5 \%$ were categorized as English Language Learners in the 201516 school year [9]. Simply translating curricula and software into multiple languages is insufficient to deal with our city's variability in learners' linguistic backgrounds which includes 155 languages other than English [9]. Students use a variety of language practices, and vary in terms of country of birth, educational history, race, and language, among other factors [10]. Because of this diversity within the population and because this diversity is not static, schools implementing NYC's CS4All policy must come to understand their students' languaging practices, and devise responsive and flexible approaches to CS curriculum design and implementation.

To address these challenges, the PiLaCS RPP brought together New York City-based university researchers with teachers at three public schools in the Washington Heights neighborhood of Manhattan. Multilingualism is woven into the fabric of that community. Forty-eight percent of area residents are foreign-born, with twothirds of them from the Dominican Republic. The neighborhood is within the NYC DOE's District 6, which had the highest share of students classified as ELLs in the City (nearly 29 percent) [1]. This study focuses in on one of the schools that participated in the RPP in the 2017-18 school year: a public 6th-8th grade middle school where $51 \%$ of the student population was categorized with the ELL designation that year. At this school, parents and caregivers of Spanish-speaking emergent bilingual students can opt their children into a bilingual program, where the school policy is to alternate the language of instruction between Spanish and English by day. This paper will focus on data from two sixth and seventh grade dual-language arts classes where teachers and students tend to use language flexibly despite the official language allocation policy. (Other schools in the project integrated CS into other subjects such as Science.)

\subsection{Our Curriculum Design Lenses and Process}

Teachers and researchers in the RPP co-designed CS-integrated units of study, taking into consideration students' language backgrounds, language objectives they were expected to meet in English and Spanish, content objectives in Language Arts, and computational thinking (CT) objectives. Our team designed projects for students to complete within the Scratch programming environment and community, because it is available in more than 40 languages, and can be used in many disciplines and kinds of projects. As we selected the CT objectives to focus on in the units, we drew on Brennan et al.'s [6] definition of CT in Scratch, which includes concepts (e.g. loops and conditionals), practices (e.g. debugging and remixing), and perspectives (e.g. participating in computing to express, connect, question).

Two other key concepts framing the collaborative design process were translanguaging pedagogy and literate programming [20]. Translanguaging pedagogy-the idea that teachers should leverage students' dynamic language resources to support their learning - 
has been applied in many teaching and learning fields to advance equity in education, especially for emergent bilinguals [11]. Traditional bilingual pedagogies focus on the extent to which students' practices conform to standard named languages, locating "problems" in students that schools could "fix" [33]. Translanguaging pedagogy instead embraces speakers who have been traditionally marginalized for their language practices in education and policy. This pedagogy encourages teachers to understand and build on students' repertoires [12], much in the way that culturally relevant and responsive models ask teachers to build on students' cultural practices [21, 22]. Culturally relevant [14] and responsive [31] computing approaches have been readily taken up in the CS education community as part of efforts to broaden participation in the field. In this study, we applied translanguaging pedagogy to the design of CS learning environments to promote equity in this discipline for emergent bilinguals. Our other guiding principle, literate programming, is a concept many associate with Donald Knuth's programming environments, which supported turning English into pseudocode, and finally into computer code plus embedded comments. His broader philosophy helps us view programming not as the mere construction of code for a computer to execute, but as texts humans will read, write, and discuss, just as people interact around other texts.

With these lenses in mind, we developed curriculum that provided multiple opportunities for students to draw upon their language resources and to communicate about, with, and through code. First, teachers described their knowledge of students and their languages practices. Then, they surfaced the specific subjectarea content objectives that they were expected to cover in their typical units of study. Together, we discussed how language and content objectives might be enhanced through integration with CS and students' interests and practices. This process led to unique CS-integrated unit plans which were relevant to students' experiences and language resources. At the school in this study, we were inspired by another initiative at the school that had brought authors of young adult novels to classrooms to read and dialogue with students. Sixth and 7th grade language arts students produced three Scratch projects: a remix of a simple "telenovela" dialogue, a remix of a project where users could practice conducting a bilingual "interview" of a character or an author of a story they read, and a "talk show" style project featuring a bilingual dialogue between book characters or authors. Teachers planned individual lessons in the unit to ensure that there were ample opportunities for students to make sense of code through writing, drawing, and speaking about it bilingually, for example, though annotations of code printed on paper, and the commenting feature within Scratch.

\section{RESEARCH QUESTIONS AND METHODS}

The research question guiding our analysis was: how, when, and why do students translanguage (draw on a range of linguistic, social, and semiotic resources) as they learn computational thinking? Given that not much is known about the performance of emergent bilinguals in CS education, our study seeks to explore the terrain: we are not interested in evaluating a particular intervention against a set of criteria, but rather, aim to better describe students' language use. For this, our study follows a naturalistic, qualitative descriptive paradigm [23]. We draw from a methodology in applied linguistics called "moment analysis" [34], which seeks to analyze the creativity and criticality of multilinguals' language-in-use at important "translanguaging moments" as well as research participants' sensemaking and metacommentary about those practices.

To conduct moment analysis, the researcher collects both recordings of naturally occurring interactions and metalanguaging data the commentary of language users about their language practices and decisions. In this study, researchers conducted 50 hours of classroom observation during periods when teachers were conducting the CS-integrated units. During observations, researchers recorded field notes and audio of whole class discussions, and of small groups of particular focal students at work on unit activities. We took photographs of students' screens, and collected student work samples. We also conducted focus groups with students, which combined questions from artifact-based interviews [7] - meant to elicit communication about particular computational thinking practices like remixing, debugging, and experimenting - with questions meant to elicit students' meta-commentary about their language choices.

The findings we present below were generated through a series of analysis procedures. We flagged moments in our field notes and student work samples that showcased the creativity of students' translanguaging, and/or their engagement with computational thinking. We brought some of these examples to the broader RPP team to reflect upon. Two collaborative descriptive inquiry sessions (CDI) [17] were conducted with our team's teachers and researchers, centered around these artifacts. CDI protocols set out a focus question, ask those present to first describe using nonevaluative language what they noticed, and then to use those noticings to prompt inferential answers to the focus question, plus recommendations and action. During CDI sessions, researchers and teachers from these schools and others described student work examples and commentary from focus groups, sharing what we thought they demonstrated about students' learning.

\section{FINDINGS}

Our analysis substantiated four "existence proof" claims about student translanguaging. We saw that 1) students' translanguaging practices in CS learning contexts blur linguistic, disciplinary, and modal boundaries, 2) computational literacies are intertwined with the many other literacies students bring with them, 3) students' language attitudes and activity contexts around them play a role in their translanguaging, and 4) students translanguage in order to engage in specific $\mathrm{CT}$ practices (like remixing and abstraction). In the section below, we describe sample critical moments that illustrate each of these claims. Due to space limitations we can not include all of the relevant critical moments supporting these claims, however, we detected no contradictory examples in our much larger dataset of field notes and analytic memos.

\subsection{Moment 1: "Predicting" Code}

In one activity, seventh graders were given "Scratch cards"-a resource produced by the Scratch Education community to serve as starter "recipes" for projects. These particular cards were written in English. Students were asked to predict on a sticky note what they thought the code on the card would make happen on the screen. 


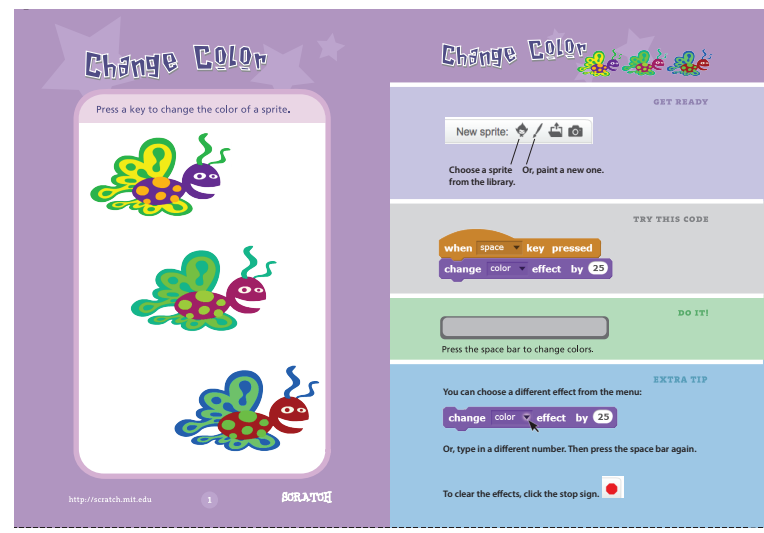

Figure 1: The Scratch card that Julio used to make his stickynote prediction.

One student Julio, who had arrived in New York from the Dominican Republic the previous school year, wrote: "El personaje cabia el color conforme a la vanderita por ejemplo: rojo azul y verde. Son mi predision." Translation: "The character changes color along with the little flag, for example, red blue and green, is my prediction."

This example supports claims one and two. First, it demonstrates how students' translanguaging blurs linguistic boundaries between named languages. Julio told us he was more comfortable using Spanish over English. At the same time, he drew on the English he knew and English/Spanish cognates such as color/color to help him interpret the English text and Scratch codes on the card. He then recast his understanding of the English card on his sticky note in a way that made sense to him (using Spanish). In this example, Julio also translanguaged "beyond" named languages. His response employs the word "vanderita" a term that he and peers spontaneously generated to refer to the green flag button in Scratch ("vanderita" is a diminutive form of the Spanish word bandera, meaning flag, spelled phonetically by Julio). Even if his response is written using language forms that might not appear in formal dictionaries, he is using his repertoire to help him make meaning of the code. Julio may also be interpreting the graphic features of the Scratch card, such as the images of the butterfly changing color. Supporting claim two is the idea that his response features words that are frequently employed in the language arts discipline, such as "el personaje" (the character) and "predision" (prediction, spelled by Julio in Spanish with invented spelling). By drawing on all of his linguistic and semiotic resources - including English/Spanish cognates, images, and discipline-specific words Julio expresses his budding understanding of concepts such as how computer programs include events that trigger various behaviors.

\subsection{Moment 2: "I don't like Spanish"}

In one activity, students were asked to remix a simple project where two sprites dialogue in Spanish with each other in a kind of "telenovela." As Jack, a sixth grade student who said he grew up in the US but identified as Dominican, was working on his remix, he expressed that he wanted to change the conversation to English, stating: "I don't like Spanish, it's too hard." Many of the peers he called on for support with his project, however, typically used Spanish in their interactions with him. One student spoke in mostly Spanish as she showed him how to use Google Translate to change the text strings of his project from one language to another.

As the unit progressed, Jack wanted to share his work on Scratch with his peers, and it became necessary for him to translanguage. At times he used English words he knew his bilingual peers would understand, at other times, he practiced oral and written Spanish, supplementing words with gestures (pointing at particular parts of the screen), and also engaging with them digitally through "likes" on Scratch projects (selecting the heart or star icons on project pages). In one instance Jack observed another student remixing his own project in the Spanish language interface of Scratch, then modified his own code using the English language interface to match hers. (Scratch's interface allows changing not only the user interface elements between English and many other languages, it also changes the keywords displayed on the code blocks.)

Jack's teacher, knowing he was reluctant to practice Spanish, consciously paired him with a student who more often used Spanish, and would benefit from Jack's preference for English. In this way, both students had authentic contexts for practicing new language, and in the end, Jack's remix featured a great deal of Spanish text, which helped him ensure his work would be accessible to his classmates. After presenting his project to the class, he stated: "When I was working with [female student], she was helping me with some of the words, because they were had misspellings in Spanish. And I was helping her with the ones that she had misspellings in English... I liked peer editing because I need help sometimes with my grammar."

This example supports our third claim that students' language attitudes and the activity contexts around them play a role in their translanguaging. Jack's initial attitude made him resistant to use Spanish in his Scratch projects and interactions with peers around Scratch. As he discovered, given his peers' language preferences and his desire to share his Scratch project and process with them, he would benefit from occasionally using language he found "too hard." The teacher's strategic pairing of Jack with a student more comfortable using Spanish pushed both students to practice new forms of language, expanding their repertoires.

\subsection{Moment 3: Interviewing a bachatero}

In one activity, students were shown an interactive Scratch project in which the user simulates interviewing the author of a novel through multiple choice Q\&A. The teachers at this school recommended that students remix the project by choosing a different author or book character to interview-but students had other ideas. Students selected figures from sports such as Stephen Curry, or pop culture, like Nicki Minaj and the reggaeton artists, Bad Bunny and Osuna. One 7th grade student, Diani, decided she wanted users of her project to interview her favorite bachata singer, Romeo Santos. This required her to draw on what she knew about this artist to ask him informed questions, and to import photos from the internet. This detail provides evidence for our second claim, that students think about computational practices such as remixing in integrated ways with their own interests and literacy practices they are familiar with - in this case, her knowledge of pop culture. As Diani planned 


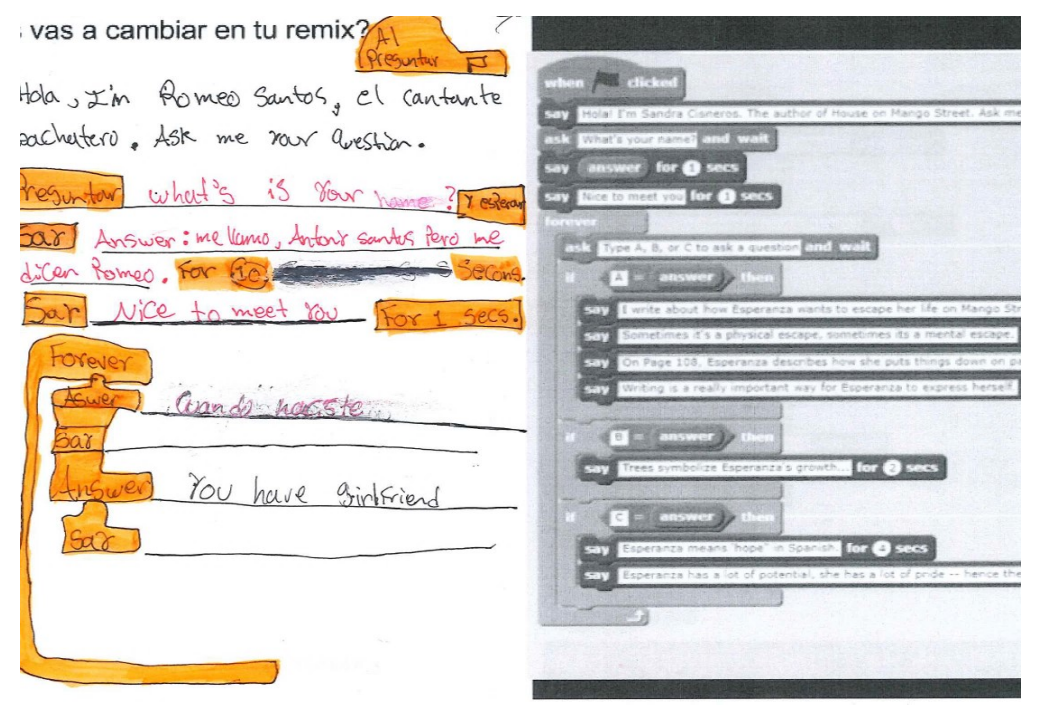

Figure 2: The remix plan that Diani drew on paper before coding in Scratch.

her remix of the "Meet the Author" project, her teacher gave her an opportunity to look at the code for the project - represented with English code blocks on the right side of a handout - and to plan out her modifications on the left side of the handout before using the digital Scratch interface. To complete this task, Diani engaged in translanguaging across linguistic and modal boundaries, supporting our first claim. She translanguaged across named language boundaries because the subject of her interview was himself, a wellknown bilingual person. For this, her character Santos "says" to users: "Hola, I'm Romeo Santos, el cantante bachatero [the bachata singer]. Ask me your question," and the questions she would enable users to ask the singer included: "What's is your name?" "Cuando naciste" [When were you born?] and "You have girlfriend."

The representation of her remix plan also employed modes beyond written language. She drew representations of Scratch code blocks using English keywords (the "say... for one sec" and "forever" blocks in the figure). While the handout was printed in black and white, Diani colored certain code blocks in orange corresponding to the color of many common Scratch blocks. She also drew invented blocks which featured Spanish and English keywords, such as the first orange block pictured at the top of her drawing which has the keywords "Al preguntar [flag]," which would literally translate to "When you ask the flag." This representation combines the "Al presionar [flag]" block and the "preguntar" blocks in the Spanish interface of Scratch ("When [flag] clicked" and "ask" blocks in the English interface.) The way she translanguages across modal and linguistic boundaries in this example is reminiscent of the way beginning writers sound out words and use invented spelling to help them write a story. This aspect of the classroom moment demonstrates the range of linguistic and modal resources students draw upon, supporting claim 1.

Further down the page, she combined the commands "answer - say - answer" in a representation of a block next to English and Spanish text of questions she wanted Santos to answer. While there is no such code block, it captures a simple algorithm for a backand-forth conversation between people in an interview. In this instance, Diani translanguages as she employs the computational thinking practice "abstraction," or creating steps to represent the real-world phenomena she is interested in. Diani translanguages as she plans her remix and engages in abstraction. This moment supports our fourth claim that students translanguage in order to engage in specific CT practices.

\subsection{Moment 4: Bilingual conversation with Shakira}

In a second project, students were asked to use Scratch to portray a dialogue between an interviewer and a character of a book. Julio and his partner, Yadira, decided their interviewee would be Esperanza, the main character of the novel House on Mango Street. They took their time deciding who the interviewer would be. First, they discussed choosing Nicki Minaj, the pop singer, but decided against it since she only speaks English. They then considered a Spanish-speaking pop singer, but decided that her particular accent in Spanish would be too difficult for them to emulate when recording. It was important to the students that they be able to provide the voices for these characters. Shakira, they determined, would be the perfect person to interview Esperanza, because she can bridge two languages, and would help amplify the audience of their Scratch project. When asked why it was important that the interviewer speak both languages, Julio responded, "porque también la gente que hable inglés también al verlo puede entender un poco de lo que se está hablando y la gente que hable español también no se desincluye" [because people who also speak English can understand a little bit of what's being talked about, and the people who speak Spanish also won't be excluded.] The dialog between Julio and Yadira as they discuss their chosen characters, and Julio's comments describing why he values the bilingualism in his project, supports claim three that students' language attitudes and the activity context play a role in translanguaging. We also 


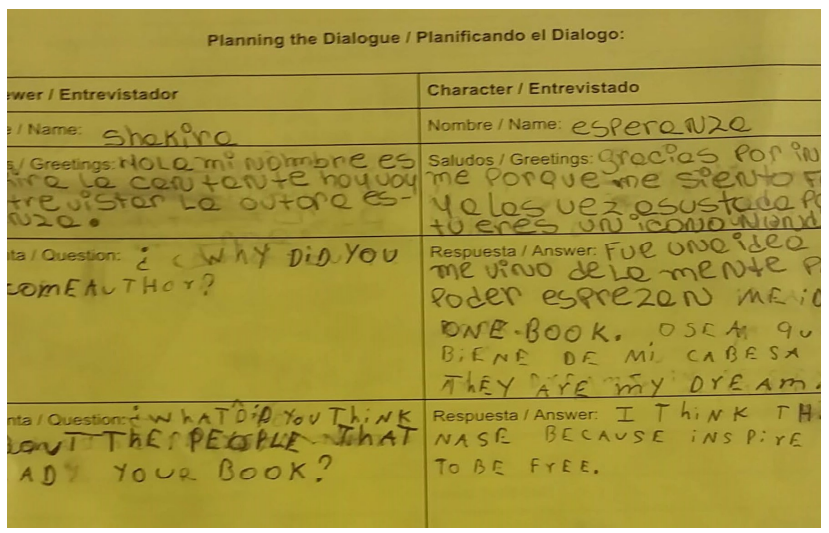

Figure 3: Julio and Yadira's script for their Scratch dialogue, featuring Shakira.

see students' translanguaging help them use computing to express and connect with local audiences - key computational thinking perspectives [6], supporting claim 4.

Julio and Yadira wrote a script for their characters using both English and Spanish. Given they wanted to ask at least one question using all English, they chose to practice writing out the standard English sentence structure for questions. As they recorded (and re-recorded) their dialogue as audio in the "sound" section of the Scratch software, the students translanguaged between modes their written text, and their oral interpretation of it. Students drew on disciplinary literacies that are encouraged in their language arts class (making inferences about characters' emotions based on text-based evidence) as they imagined how the character's tone of voice would change if she were to meet the famous Shakira. As they sequenced the code blocks to animate their sprites, their speech was peppered with Scratch keywords in both Spanish and English. Throughout the planning process and as they built their project, this pair of students translanguaged across and beyond named languages, modalities, and code (supporting claim 1).

\section{DISCUSSION}

Guided by the theory of translanguaging, this study aimed to document the diverse language practices of bilingual students, and to validate them as meaning-making resources in computer science education. Through moment analysis, we generated four claims that we illustrated with examples, namely: 1) that students' translanguaging practices in CS learning contexts blur linguistic, disciplinary, and modal boundaries, 2) computational literacies are intertwined with the many other literacies students bring with them, 3) students' language attitudes and activity contexts around them play a role in their translanguaging, and 4) students translanguage in order to engage in specific CT practices (like remixing and abstraction).

Similar to the literate programming philosophy, we see evidence that students can and do use their full linguistic repertoire as they leverage into new competencies and discourses. They express computational ideas through code and many other associated representations such as sprites, audiofiles, text and so on. These ideas are not divorced from other literacies the students bring to bear, whether it is their literacy in the norms and forms of a telenovela, or their understandings of how to craft a message for a particular audience. Nor are their computing practices divorced from their values about languages and bilingualism. Students' computing in this project was driven by their desire to connect with their bilingual peers who had varying experiences with English and Spanish, which meant their choices about sprites and scripts were tied up with their perceptions of their own and others' language use. Moreover, as students came to value their own fluency in Scratch, it was deeply influenced by how that skill intersected with their cultural, linguistic, and disciplinary literacies.

Our original research question asked about the use of translanguaging while students learn computational thinking. In the classroom profiled in this study, doing computer science meant becoming a part of the classroom community though use of multiple named languages, code, and shared references to pop culture and books. These moments shifted our view away from translanguaging as a process that co-occurs with or mediates learning computational thinking, and encouraged us to begin considering computational literacies as the real goal, through the lens of translanguaging. By "computational literacies" we mean ways of creating and communicating about, with, and through computational artifacts (like code, datasets, and models) for particular purposes, and in and for communities. In this way, computation is participating in a community of discourse, i.e., being able to co-construct meaning with a larger community of interlocutors [18]. Viewing CS as participating in computational literacies prompts educators to ask the question: "What conversation is this code a part of?"

Translanguaging has implications not only for how emergent bilingual students use home language and English as they participate in computational literacies, but also how all students, including monolingual students, leverage across and beyond human and computational languages and representations. It also means that educators should not treat computer science education as pursuing fixed learning progressions of computational concepts with 'remediation' or 'differentiation' for emergent bilinguals. Rather, educators must think more about how to join the varied literacies students bring to the classroom with potential computational literacies they could participate in through translanguaging. This is as true for teachers of monolingual learners as it is for emergent bilinguals, since each student brings their distinct repertoires and values to the domain of computation. Translanguaging provides an important lens to help us describe and support this process. Understanding students' translanguaging can help teachers design CS projects and lessons that support all learners more equitably.

\section{ACKNOWLEDGMENTS}

The authors would like to thank the students and teachers that participated in this research. This material is based on work supported by the US National Science Foundation under Grant Nos. CNS1738645 and DRL-1837446. Any opinions, findings, and conclusions or recommendations expressed in this material are those of the author(s) and do not necessarily reflect the views of the National Science Foundation. 


\section{REFERENCES}

[1] 2015. An Economic Snapshot of Washington Heights and Inwood. Technical Report 2-2016. Office of the State Comptroller, New York City. https://www.osc.state. ny.us/osdc/rpt2-2016.pdf

[2] 2016. A Framework for K-12 Computer Science Education. https://k12cs.org/

[3] 2017. Common Core of Data: America's Public Schools. Technical Report. National Center for Education Statistics. https://nces.ed.gov/ccd/tables/ACGR_RE_and_ characteristics_2015-16.asp

[4] 2017. Supporting the Study of World Languages and Computer Science. https://www.actfl.org/news/position-statements/ supporting-the-study-world-languages-and-computer-science

[5] 2018. The Condition of Education: English Language Learners in Public Schools. Technical Report. National Center for Education Statistics. https://nces.ed.gov/ programs/coe/indicator_cgf.asp

[6] Karen Brennan, Michelle Chung, Wendy Martin, Francisco Cervantes, Bill Tally, and Mitchel Resnick. [n. d.]. Computational Thinking With Scratch. Online. Harvard Graduate School of Education and the Education Development Center Inc. http://scratched.gse.harvard.edu/ct/index.html

[7] Karen Brennan and Mitchel Resnick. 2012. Using artifact-based interviews to study the development of computational thinking in interactive media design Vancouver, BC, Canada. http://scratched.gse.harvard.edu/ct/files/AERA2012.pdf

[8] Virginia P. Collier and Wayne P. Thomas. 2017. Validating the Power of Bilingual Schooling: Thirty-Two Years of Large-Scale, Longitudinal Research. Annual Review of Applied Linguistics 37 (Sept. 2017), 203-217. https://doi.org/10.1017/ S0267190517000034

[9] Division of English Language Learners and Student Support. 2018. English Language Learner Demographics Report for the 2016-17 School Year. Technical Report. New York City Department of Education, New York, NY. http://schools. nyc.gov/NR/rdonlyres/3A4AEC4C-14BD-49C4-B2E6-8EDF5D873BE4/223369/ 201617DemographicReportFINALSpring20191.pdf

[10] Ofelia García. 2009. Bilingual Education in the 21st Century: A Global Perspective (1 edition ed.). Wiley-Blackwell, Malden, MA ; Oxford.

[11] Ofelia García, Susana Ibarra Johnson, and Kate Seltzer. 2017. The Translanguaging Classroom: Leveraging Student Bilingualism for Learning. Caslon Publishing, Philadelphia.

[12] Ofelia García and Tatyana Kleyn (Eds.). 2016. Translanguaging with Multilingual Students: Learning from Classroom Moments. Routledge, New York.

[13] Ofelia García and Li Wei. 2014. Translanguaging: Language, bilingualism and education. Palgrave Macmillan Pivot, London, United Kingdom. http://www.palgrave.com\%2Fpage\%2Fdetail\%2Ftranslanguaging-ofelia-garcia\% 2F\%3Fisb\%3D9781137385758

[14] Joanna Goode and Jane Margolis. 2011. Exploring Computer Science: A Case Study of School Reform. TOCE 11, 2 (2011), 12. https://doi.org/10.1145/1993069. 1993076

[15] Grantmakers for Education. 2013. Educating English Language Learners: Grantmaking Strategies for Closing America's Other Achievement Gap. Technical Report. https://edfunders.org/sites/default/files/Educating\%20English\% 20Language\%20Learners_April\%202013.pdf

[16] Shuchi Grover and Roy Pea. 2013. Using a Discourse-intensive Pedagogy and Android's App Inventor for Introducing Computational Concepts to Middle School Students. In Proceeding of the 44th ACM Technical Symposium on Computer Science Education (SIGCSE '13). ACM, New York, NY, USA, 723-728. https: //doi.org/10.1145/2445196.2445404

[17] Margaret Himley and Patricia F. Carini. 2000. From Another Angle: Children's Strengths and School Standards : the Prospect Center's Descriptive Review of the Child. Teachers College Press. Google-Books-ID: ERNnJChzRywC.
[18] Chris Hoadley and S Favaro. [n. d.]. Digital literacy in higher education. In The SAGE Encyclopedia of Educational Technology (1 edition ed.), J. Michael Spector (Ed.). SAGE Publications, Inc, 221-223.

[19] Megan Hopkins. 2016. Beliefs in context: Understanding language policy implementation at a systems level. Educational Policy 30, 4 (2016), 573-605. http://journals.sagepub.com/doi/abs/10.1177/0895904814550073

[20] D. E. Knuth. 1984. Literate Programming. Comput. f. 27, 2 (Jan. 1984), 97-111. https://doi.org/10.1093/comjnl/27.2.97

[21] Gloria Ladson-Billings. 1995. But that's just good teaching! The case for culturally relevant pedagogy. Theory into practice 34, 3 (1995), 159-165. http://www. tandfonline.com.ezproxy.gc.cuny.edu/doi/pdf/10.1080/00405849509543675

[22] Gloria Ladson-Billings. 2007. Pushing Past the Achievement Gap: An Essay on the Language of Deficit. Fournal of Negro Education 76, 3 (2007), 316-323.

[23] Lincoln, Yvonna S. and Guba, Egon G. 1985. Naturalistic Inquiry (1st edition ed.). SAGE Publications, Beverly Hills, Calif.

[24] Kate Menken. 2010. NCLB and English Language Learners: Challenges and Consequences. Theory Into Practice 49, 2 (April 2010), 121-128. http://dx.doi. org $/ 10.1080 / 00405841003626619$

[25] Kate Menken, Tatyana Kleyn, Laura Ascenzi-Moreno, Nabin Chae, Nelson Flores, and Alexander Funk. 2009. Meeting the Needs of Long-Term English Language Learners in High School, Phase II. Technical Report. Report submitted to New York City Department of Education.

[26] Kate Menken and Cristian Solorza. 2015. Principals as linchpins in bilingual education: The need for prepared school leaders. International fournal of Bilingual Education and Bilingualism 18, 6 (2015), 676-697. https://katemenken.files.wordpress. com/2011/10/menken-solorza-2015-principals-as-linchpins-published.pdf

[27] New York City Department of Education. [n. d.]. CS4All "Blueprint". Technical Report. New York City.

[28] Office of English Language Learners. 2013. 2013 Demographic Report. Technical Report. New York City Department of Education, New York, NY. http: //schools.nyc.gov/NR/rdonlyres/FD5EB945-5C27-44F8-BE4B-E4C65D7176F8/ 0/2013DemographicReport_june2013_revised.pdf

[29] Ricardo Otheguy, Ofelia García, and Wallis Reid. 2015. Clarifying translanguaging and deconstructing named languages: A perspective from linguistics. Applied Linguistics Review 6, 3 (2015), 281-307. https://doi.org/10.1515/applirev-2015-0014

[30] Yogendra Pal and Sridhar Iyer. 2015. Classroom Versus Screencast for Native Language Learners: Effect of Medium of Instruction on Knowledge of Programming. In Proceedings of the 2015 ACM Conference on Innovation and Technology in Computer Science Education (ITiCSE '15). ACM, New York, NY, USA, 290-295. https://doi.org/10.1145/2729094.2742618

[31] Kimberly A. Scott, Kimberly M. Sheridan, and Kevin Clark. 2015. Culturally responsive computing: a theory revisited. Learning, Media and Technology 40, 4 (2015), 412-436. http://www.tandfonline.com.ezproxy.gc.cuny.edu/doi/abs/10. $1080 / 17439884.2014 .924966$

[32] Adalbert Gerald Soosai Raj, Kasama Ketsuriyonk, Jignesh M. Patel, and Richard Halverson. 2018. Does Native Language Play a Role in Learning a Programming Language?. In Proceedings of the 49th ACM Technical Symposium on Computer Science Education (SIGCSE '18). ACM, New York, NY, USA, 417-422. https: //doi.org/10.1145/3159450.3159531

[33] Richard R. Valencia. 2010. Dismantling contemporary deficit thinking: Educational thought and practice. Routledge, New York \& London. https://books-google-com. ezproxy.gc.cuny.edu/books?hl=en\&lr=\&id=80tZBwAAQBAJ\&oi=fnd\&pg= PP1\&ots=RIXnFaVYlx\&sig=XxQZsK_KNg66wj3bxzoQ6aL9Qp8

[34] Li Wei. 2011. Moment Analysis and translanguaging space: Discursive construction of identities by multilingual Chinese youth in Britain. Fournal of Pragmatics 43, 5 (April 2011), 1222-1235. https://doi.org/10.1016/j.pragma.2010.07.035 